Supporting Information

\title{
Discovery and Pharmacological Studies of 4-Hydroxyphenyl-Derived Phosphonium Salts Active in a Mouse Model of Visceral Leishmaniasis
}

José Ignacio Manzano, ${ }^{\dagger, \# ~ E d u a r d o ~ J . ~ C u e t o-D i ́ a z, ~}{ }^{\ddagger}, \#$ Ana Isabel Olías-Molero, ${ }^{\S}$ Ana Perea, ${ }^{\dagger}$ Tomás Herraiz,,$^{\|}$Juan J. Torrado, ${ }^{\perp}$ José María Alunda, ${ }^{\S}$ Francisco Gamarro, ${ }^{*}, \dagger$ Christophe Dardonville ${ }^{*}, \star$

\section{Contents}

1) Table $S 1$

2) Table $S 2$

3) Table $\mathrm{S} 3$

4) Table $S 4$

5) ${ }^{1} \mathrm{H}$ and ${ }^{13} \mathrm{C}$ NMR spectra of compounds $\mathbf{1}-\mathbf{4}$ and 9

6) HPLC traces for compounds 1-4 and 9
Page

S2

S4

S5

S6

S7

S12 
Table S1. Activity of TAO compounds in promastigote and intracellular amastigote forms of Leishmania donovani HU3 and cytotoxicity against MRC-5 or THP-1 cells ${ }^{a}$

Structure

Ref. Cmpd

$\operatorname{EC} 50(\mu M)$

$\begin{array}{ccc}\text { L. donovani } & \begin{array}{c}\text { L. donovani } \\ \text { promastigotes } \\ \text { amastigotes }\end{array} & \text { MRC-5 cells } \\ \text { (THP-1 cells) }\end{array}$

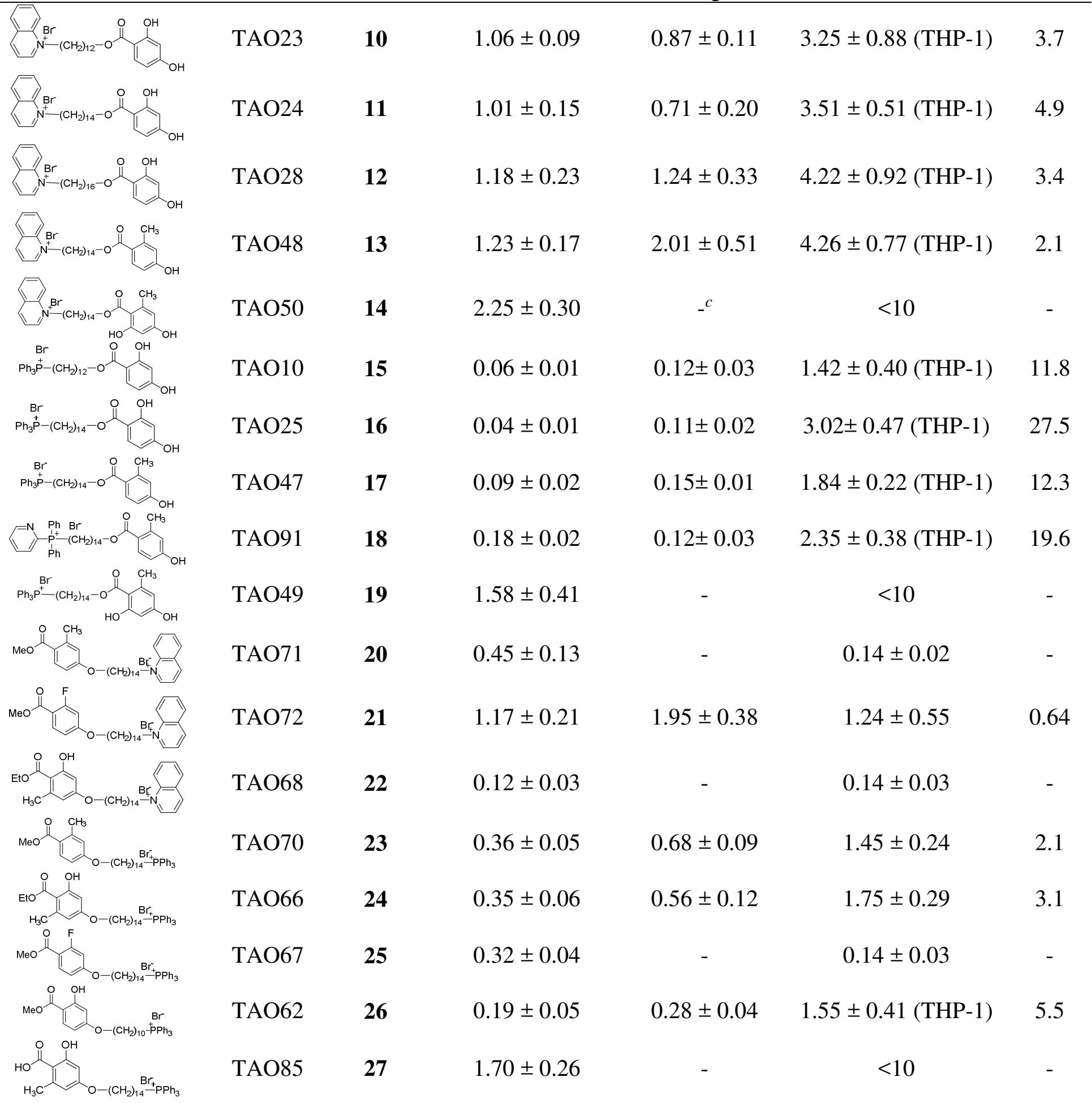




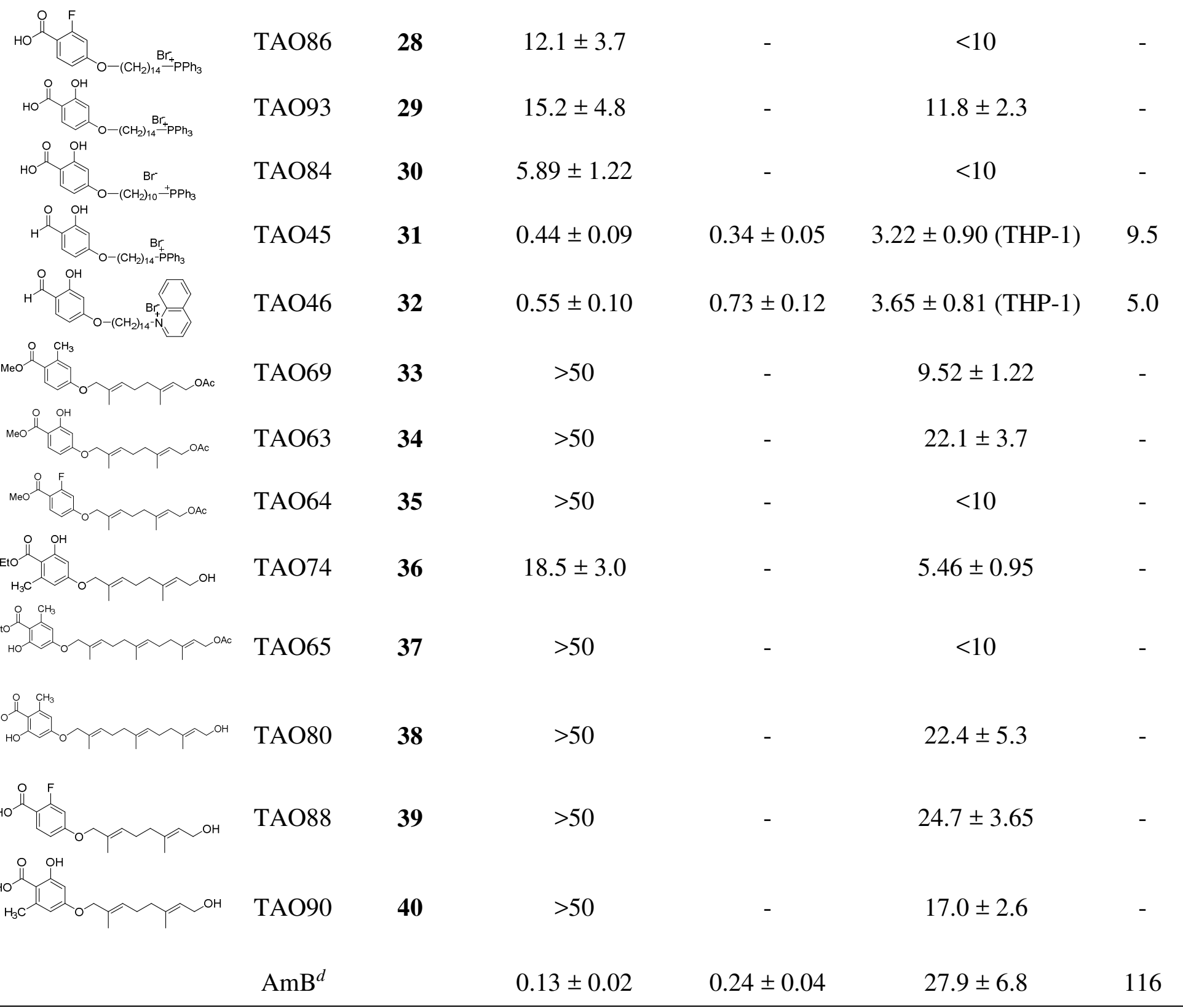

${ }^{a}$ Parasites and MRC-5 (THP-1) cells were grown in the presence of increasing concentrations of compounds. Data are means \pm standard deviations from three independent experiments.

${ }^{b} \mathrm{SI}=$ Selectivity Index (EC50 MRC-5 (THP-1) / EC50 parasite (amastigote form)). ${ }^{c}$ not tested. ${ }^{d}$ Amphotericin B. 
Table S2. Plasma concentration of compound $\mathbf{1}$ in $\mathrm{BALB} / \mathrm{c}$ mice after oral administration of $20 \mathrm{mg} / \mathrm{Kg}$ formulated in $8 \%$ DMSO in water*

\begin{tabular}{|c|c|c|}
\hline $\mathrm{T}(\mathrm{h})$ & $\mu \mathrm{g} / \mathrm{mL}$ & $\mu \mathrm{M}$ \\
\hline 0 & - & - \\
\hline 1 & 110.82 & 181.98 \\
\hline 3 & 12.18 & 19.99 \\
\hline 6 & 1.67 & 2.74 \\
\hline 24 & 2.00 & 3.29 \\
\hline 48 & 0.82 & 1.19 \\
\hline 72 & 0.57 & 0.83 \\
\hline
\end{tabular}

*Values correspond to pooled plasma samples at each sampling time. 
Table S3. Microsomal stability of compound 1 toward metabolism by cytochrome P450 (Phase-I metabolism) and Uridine Glucuronosyl-Transferase (UGT) (Phase-II metabolism) studied in presence of NADPH and UDPGA

\begin{tabular}{|c|c|c|c|c|}
\hline Fraction & Fase I/II & $\begin{array}{l}\text { Time } \\
(\min )\end{array}$ & $\begin{array}{l}\text { Compound } 1 \\
\text { (\% remaining) }\end{array}$ & $\begin{array}{l}\text { Diclofenac } \\
\text { (\% remaining) }\end{array}$ \\
\hline \multirow{5}{*}{$\begin{array}{l}\text { Human liver } \\
\text { microsomes (HLM) }\end{array}$} & \multirow[t]{5}{*}{ P450-NADPH } & 0 & 100 & 100 \\
\hline & & 15 & 80.8 & 48.7 \\
\hline & & 30 & 77.4 & 20.8 \\
\hline & & 60 & 73.8 & 7.9 \\
\hline & & 120 & 68.3 & 0.0 \\
\hline \multirow{5}{*}{$\begin{array}{ll}\text { Human } & \text { liver } \\
\text { microsomes (HLM) }\end{array}$} & \multirow{5}{*}{$\begin{array}{l}\text { UGT-enzymes } \\
\text { (UDPGA) }\end{array}$} & 0 & 100 & - \\
\hline & & 15 & 70.1 & - \\
\hline & & 30 & 59.0 & - \\
\hline & & 60 & 42.9 & -- \\
\hline & & 120 & 34.3 & - \\
\hline \multirow{5}{*}{$\begin{array}{l}\text { Mouse liver } \\
\text { Microsomes (MLM) }\end{array}$} & \multirow[t]{5}{*}{ P450-NADPH } & 0 & 100 & 100 \\
\hline & & 15 & 39.7 & 83.1 \\
\hline & & 30 & 24.0 & 76.5 \\
\hline & & 60 & 14.6 & 68.7 \\
\hline & & 120 & 0.0 & 65.3 \\
\hline \multirow{5}{*}{$\begin{array}{l}\text { Mouse } \\
\text { microsomes } \\
(\mathrm{MLM})\end{array}$} & \multirow{5}{*}{$\begin{array}{l}\text { UGT-enzymes } \\
\text { (UDPGA) }\end{array}$} & 0 & 100 & \\
\hline & & 15 & 70.4 & \\
\hline & & 30 & 49.98 & \\
\hline & & 60 & 34.99 & \\
\hline & & 120 & 24.03 & \\
\hline \multirow{5}{*}{$\begin{array}{l}\text { Human liver S9- } \\
\text { fraction }\end{array}$} & \multirow[t]{5}{*}{ P450-NADPH } & 0 & 100 & \\
\hline & & 15 & 96.2 & \\
\hline & & 30 & 95.5 & \\
\hline & & 60 & 91.8 & \\
\hline & & 120 & 93.6 & \\
\hline \multirow{5}{*}{$\begin{array}{l}\text { Human liver S9- } \\
\text { fraction }\end{array}$} & \multirow{5}{*}{$\begin{array}{l}\text { UGT-enzymes } \\
\text { (UDPGA) }\end{array}$} & 0 & 100 & \\
\hline & & 15 & 83.4 & \\
\hline & & 30 & 69.4 & \\
\hline & & 60 & 57.9 & \\
\hline & & 120 & 53.1 & \\
\hline
\end{tabular}


Table S4. Individual plasma concentration of 1 in BALB/c mice infected with $L$. infantum and uninfected animals receiving 4 doses of $30 \mu \mathrm{g}$ of compound $\mathbf{1}$ by oral gavage.

\begin{tabular}{|l|l|l|l|l|l|}
\hline \multicolumn{3}{|c|}{ Infected \& treated } & \multicolumn{3}{c|}{ Healthy \& treated } \\
\hline Sample & $\mathrm{C}(\mu \mathrm{g} / \mathrm{mL})$ & $\mathrm{C}(\mu \mathrm{M})$ & Sample & $\mathrm{C}(\mu \mathrm{g} / \mathrm{mL})$ & $\mathrm{C}(\mu \mathrm{M})$ \\
\hline 2.1 & 3.52 & 5.78 & 3.1 & 12.79 & 21.0 \\
\hline 2.2 & 16.28 & 26.74 & 3.2 & 6.60 & 10.84 \\
\hline 2.3 & 11.48 & 18.86 & 3.3 & 10.82 & 17.77 \\
\hline 2.4 & 5.43 & 8.91 & 3.4 & 5.54 & 9.10 \\
\hline 2.5 & 5.54 & 9.10 & 3.5 & 1.35 & 2.21 \\
\hline Mean \pm SD & $8.45 \pm 5.30$ & $13.88 \pm 8.71$ & Mean \pm SD & $7.42 \pm 4.51$ & $12.18 \pm 7.41$ \\
\hline
\end{tabular}


${ }^{1} \mathrm{H}$ and ${ }^{13} \mathrm{C}$ NMR spectra of target compounds $\mathbf{1}-\mathbf{4}$
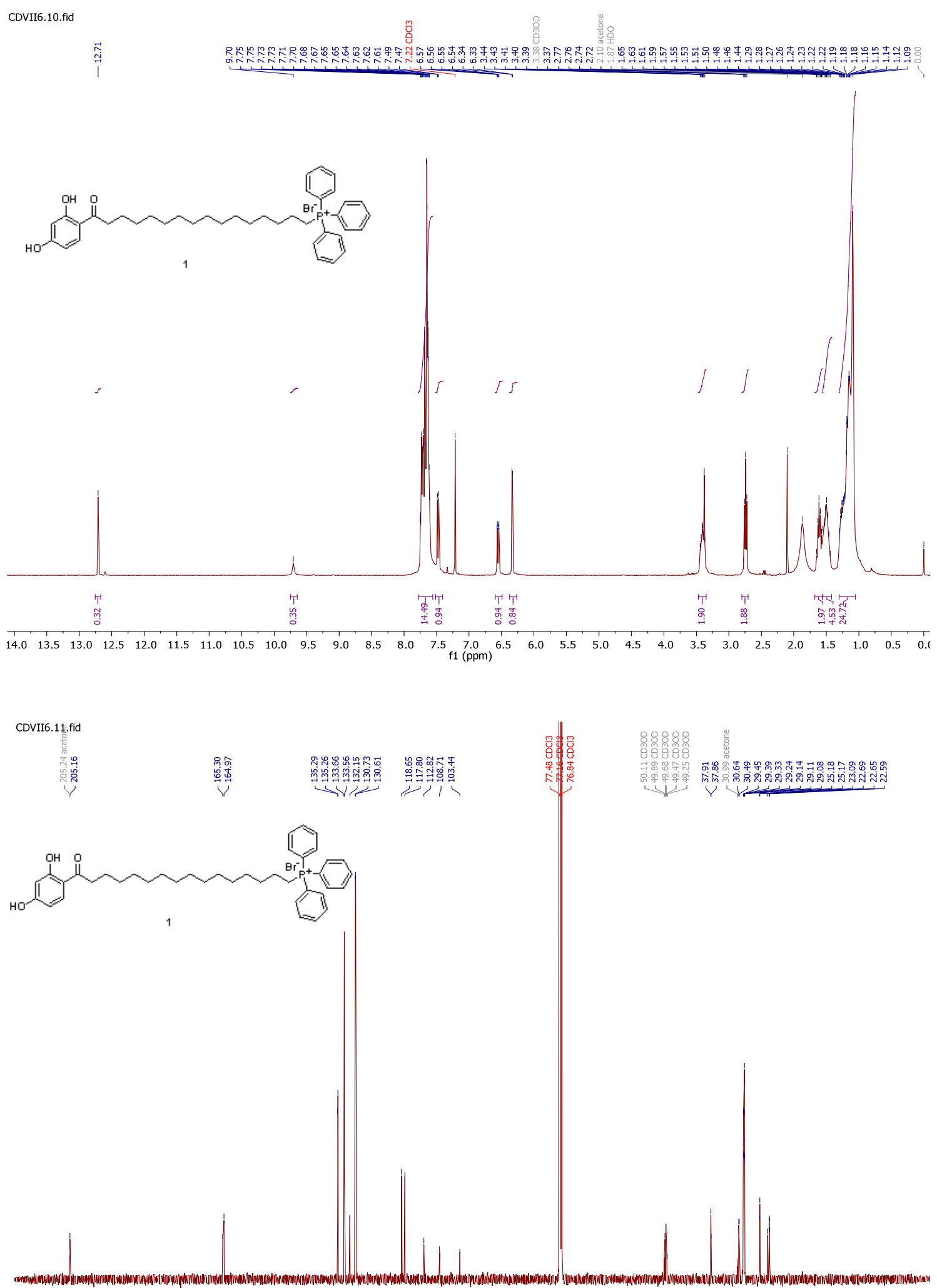

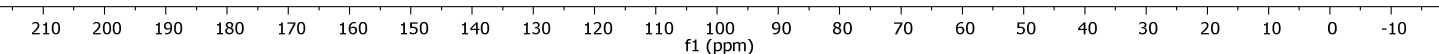



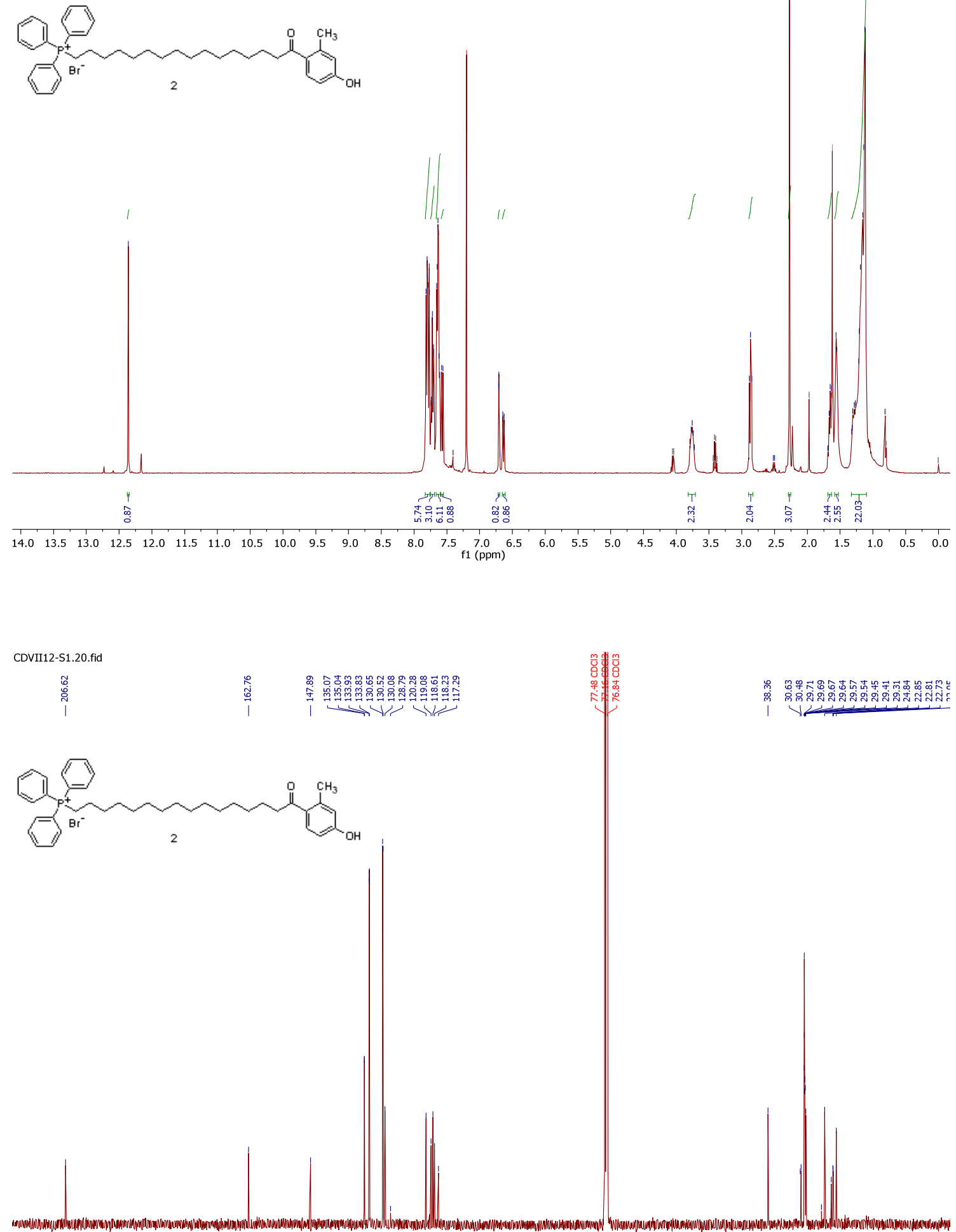

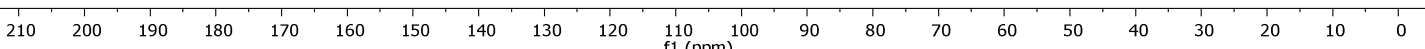



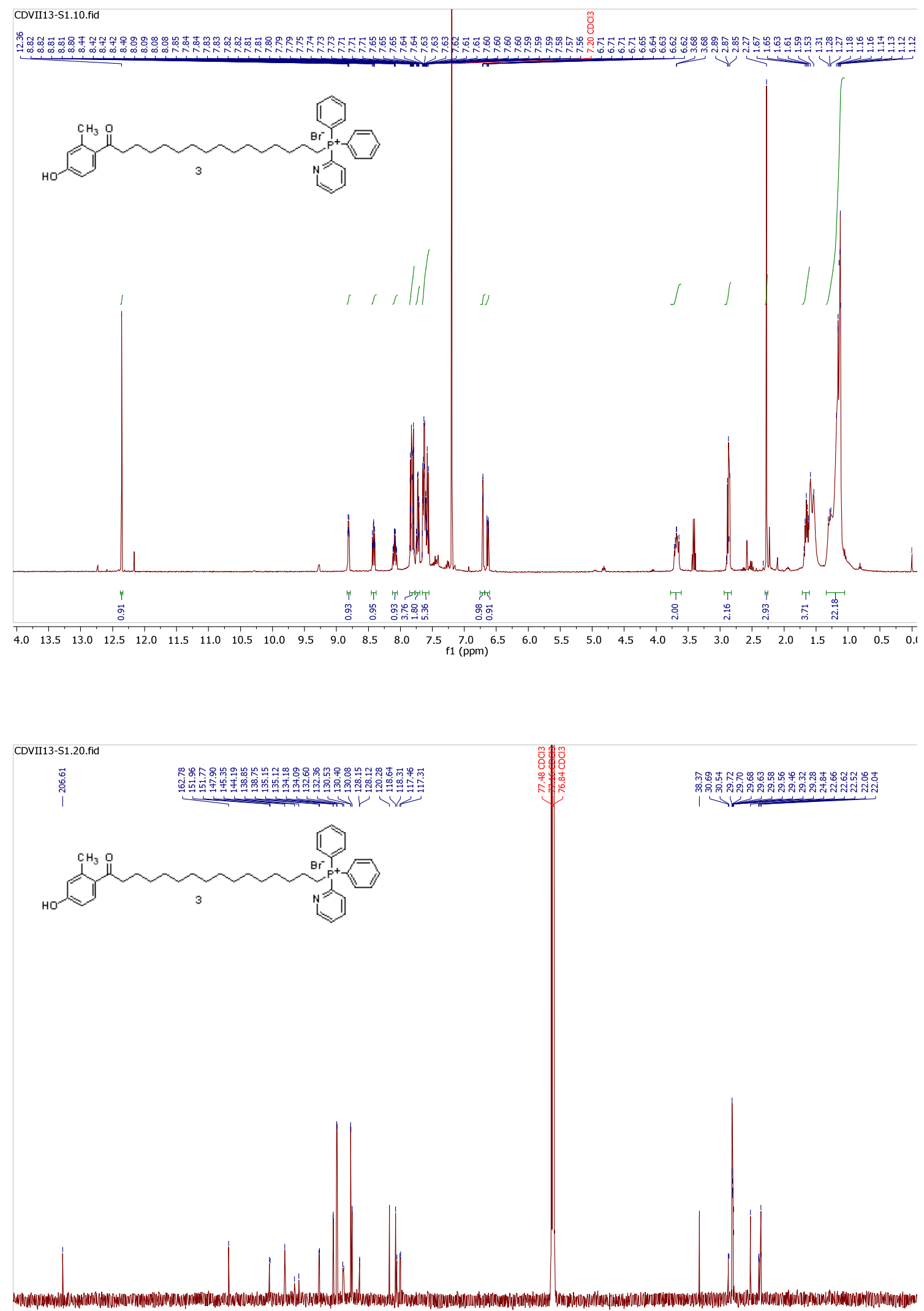

$\begin{array}{llllllllllllllllllllllllllllllll}210 & 200 & 190 & 180 & 170 & 160 & 150 & 140 & 130 & 120 & 110 & 100 & 90 & 80 & 70 & 60 & 50 & 40 & 30 & 20 & 10 & 0 & -10\end{array}$ 


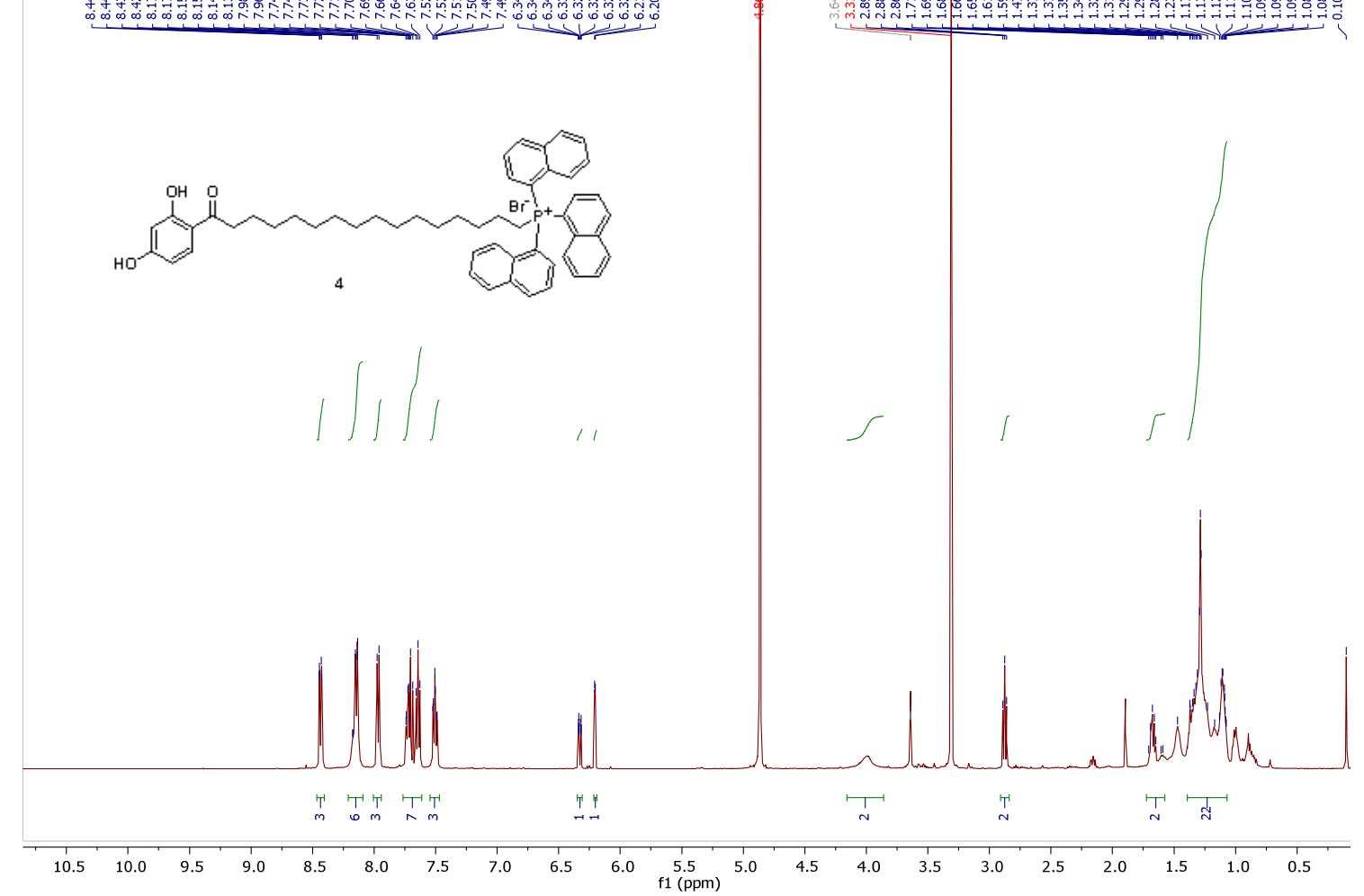

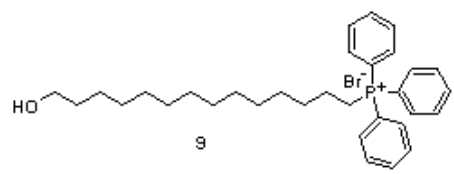

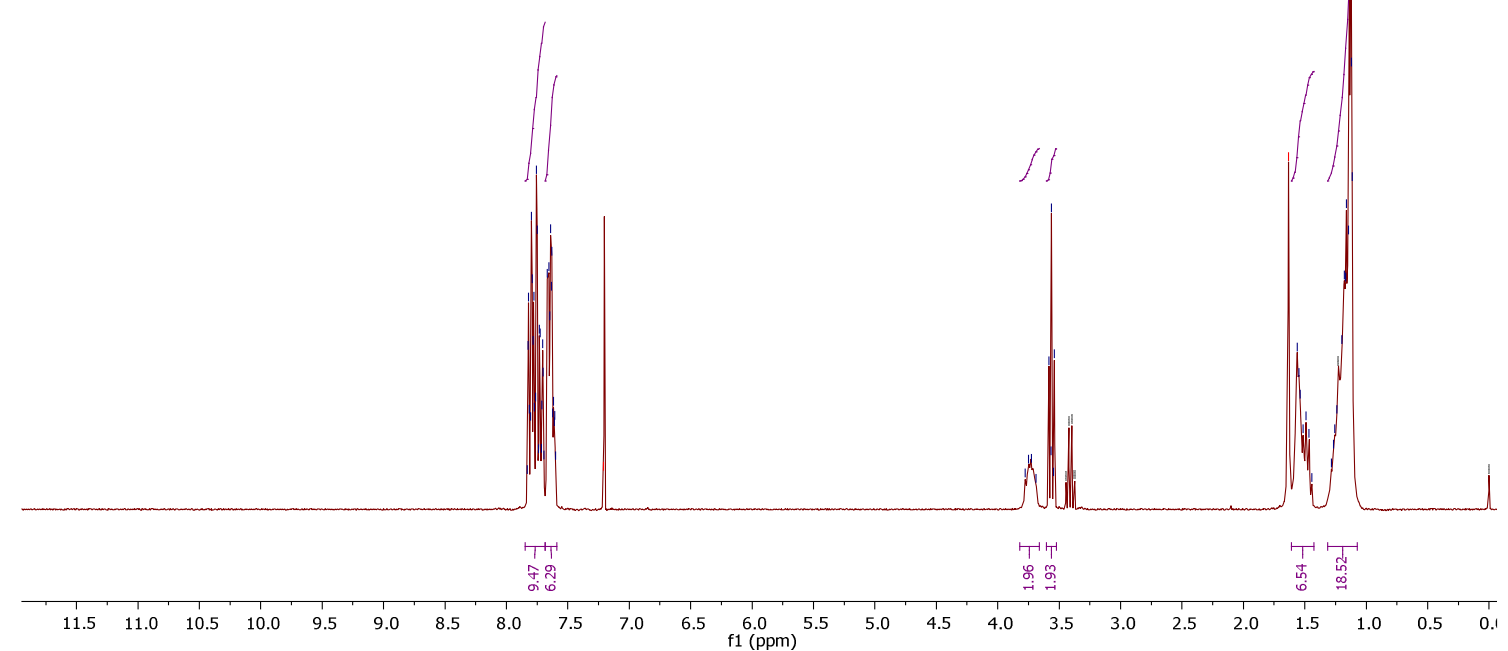




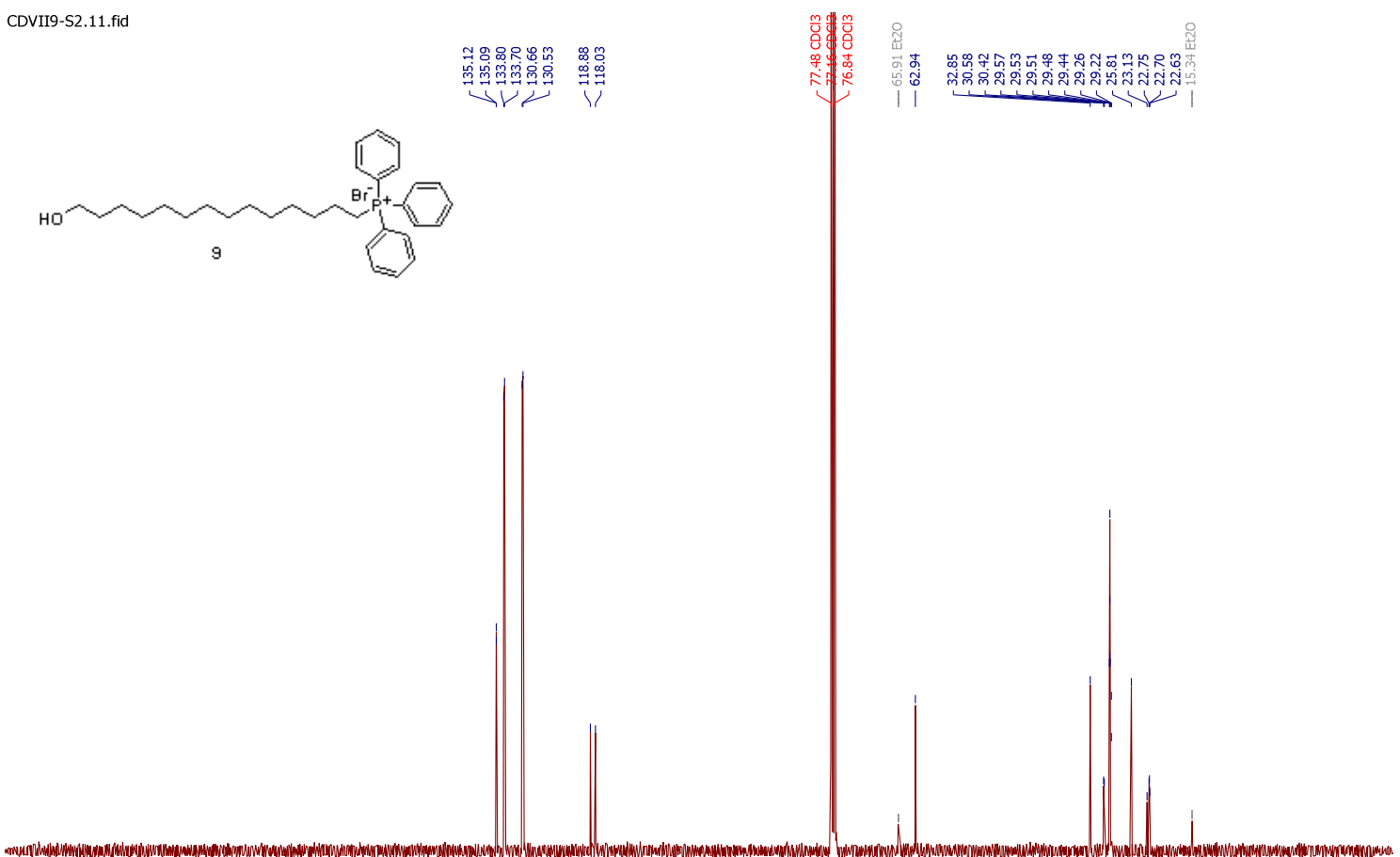

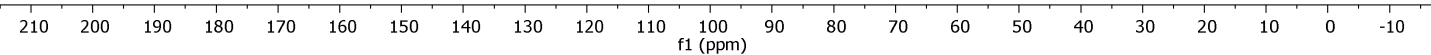


HPLC Traces of compounds 1-4 and $\mathbf{9}$
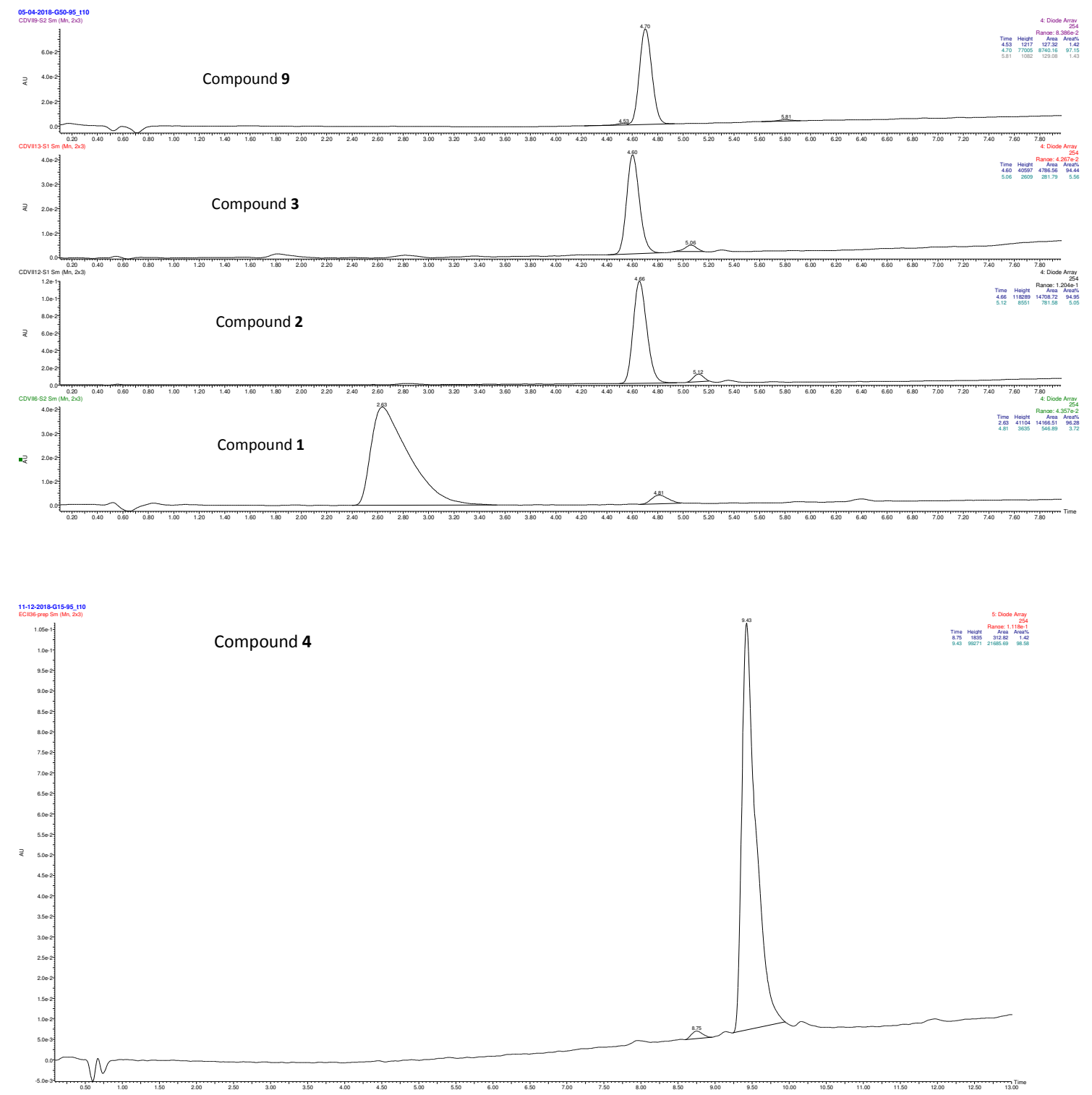